\title{
Interactive comment on "Empirical Estimation of the Spatial Sediment Transport Capacity Coefficient Using the Rain Erosivity Factor and SWAT Model Results in the Han River Basin, South Korea” by Chung-Gil Jung et al.
}

\section{Anonymous Referee \#1}

Received and published: 20 October 2017

The authors submitted the revised version of the manuscript as a new submission (first submission had manuscript number hess-2016-649). The manuscript is slightly improved. However, the main drawbacks from my point of view are written below and are similar to the ones stated in the review process of the first submission:

-The structure of the paper is still not well organized (e.g., some paragraphs should be moved from the Results and discussion section to the methodology, for example eq. 8 and eq. 9); it is still hard to understand the individual parts of the research work that has been done and consequently the paper messages are not clear. 
-Some steps of the research are still not well described, e.g., how suspended sediments were measured (eight days interval is mentioned but not explained), how was SWAT model calibrated (which method was used), etc. (more suggestions were given in the review of the first submission).

-There are a lot of small errors, e.g., the one related to the $\mathrm{K}$ factor units, on page 4: sometimes $\mathrm{K}$ factor does not have units; sometimes $\mathrm{Mg} / \mathrm{ha} / \mathrm{R}$ units are used? $\mathrm{K}$ factor units are usually tha $\mathrm{h}$ ha- $1 \mathrm{MJ}-1 \mathrm{~mm}-1$. What is the physical meaning of negative KTC values that can be seen as potential result from Fig. 12 and Fig. 10 (95\% confidence interval)?

To sum up, I suggest to reject the paper in its current form and I suggest authors to firstly take into consideration all the comments that were given in the review of the first submission since most of the issues have not been resolved.

Interactive comment on Hydrol. Earth Syst. Sci. Discuss., https://doi.org/10.5194/hess-2017553, 2017. 